\title{
The Sociological Review
}

\section{Toward a critical sociology of lifestyle migration: reconceptualizing migration and the search for a better way of life}

\section{Michaela Benson and Nick Osbaldiston}

\begin{abstract}
This article places under critical and reflexive examination the theoretical underpinnings of the concept of lifestyle migration. Developed to explain the migration of the relatively affluent in search of a better way of life, this concept draws attention to the role of lifestyle within migration, alongside understandings of migration as one stage within the ongoing lifestyle choices and trajectories of individual migrants. Through a focus on two paradigms that are currently at work within theorizations of this social phenomenon - individualization and mobilities - we evaluate their contribution to this flourishing field of research. In this way, we demonstrate the limitations and constraints of these for understanding lifestyle migration; engaging with long-standing debates around structure and agency to make a case for the recognition of history in understanding the pursuit of 'a better way of life'; questioning the extent to which meaning is made through movement, and the politics and ethics of replacing migration with mobilities. Through this systematic consideration, we pave the way for re-invigorated theorizing on this topic, and the development of a critical sociology of lifestyle migration.
\end{abstract}

Keywords: lifestyle migration, mobilities, individualism, historical sociology, migration

\section{Introduction}

Lifestyle migration is a novel extension of a phenomenon with a history, made possible as a result of global developments of the past 50 or 60 years. It relates specifically to the relative economic privilege of individuals in the developed world, the reflexivity evident in post-/late modernity, the construction of particular places as offering alternative lifestyles, and a more general ease (or freedom) of movement. (Benson and O'Reilly, 2009: 620)

Lifestyle migration is a complex and nuanced phenomenon, varying from one migrant to another, from one location to the next. It holds at its core social transformation and wider processes; it is at once an individualized pursuit and structurally 
reliant and it is a response to practical, moral and emotional imperatives. (O'Reilly and Benson, 2009: 11; italics added)

This article places under critical and reflexive examination the theoretical underpinnings of the concept of lifestyle migration. First systematically outlined by Benson and O'Reilly (2009; see also O'Reilly and Benson, 2009) in this journal to explain the migration of the relatively affluent and privileged (often white and Western) in search of a better way of life, and to systematically outline the historical, structural and material conditions that make this possible, this concept draws attention to the role of lifestyle within migration, alongside understandings of migration as one stage within the ongoing lifestyle choices and trajectories of individual migrants. Themes of reflexivity, consumption, privilege and their relationships to identity and migrant subjectivities have been key to these conceptualizations of lifestyle migration. While the concept has become the basis of a distinct field of research, it has also travelled, along the way encountering and intersecting with various paradigms within the social sciences.

While the thematic underpinnings of the research have undoubtedly influenced its theorization, we believe there is a danger that these remain unacknowledged and unchallenged within resulting research, a recurring issue for sociology more generally. Our critical evaluation of the thematic underpinnings within lifestyle migration scholarship presented here therefore intends to serve a further purpose, providing a unique example of how contemporary social theory is adopted uncritically to understand social phenomena and with what consequences. Overall, through the case of lifestyle migration we seek to demonstrate a problem identified by Inglis (2014) (amongst others) of using conceptual framings that appear fresh and innovative but which neglect important sociological tenets and precursors. From this position, we speak back to lifestyle migration scholarship, encouraging a more critical, engaged and sensitive approach to the concepts it uses.

Focusing in particular on two increasingly common themes in the current and ongoing conceptualizations of lifestyle migration, individualization and mobilities (themes also prominent in contemporary social theory), we argue that while these concepts appear to provide ready-made explanations they also run the risk of limiting understandings. As Inglis (2014: 100) argues, the ease with which we presently turn to these ready-made 'periodizing constructs' is ubiquitous. Our evaluation of individualism focuses on the need to address the historical veracity of such an approach; in particular, we contend that there needs to be some opening up of the black boxes of theoretical assumptions built into the new individualism and the privileging of 'choice' over structural analysis. Relatedly, we question the sea-change in theoretical thought from migration to mobilities (see also Favell, 2001) to argue that the ideas that permeate the mobilities literature (especially as these have been applied in the critique of lifestyle migration) provide little impetus to give up the pursuit of a (critical) sociology of lifestyle migration. We question whether taking 
such an approach deters lifestyle migration scholars from entering the broad scholarship of migration studies more generally, a dialogue that would be of benefit both to research on lifestyle migration and migration more generally (O'Reilly, 2012).

In this paper, we therefore reconsider the conceptual frameworks that guide lifestyle migration research to explore the particular tension that exists in understanding significant cultural phenomena: the ability to make sense of them by paying homage to recent 'turns' in social theoretical thought.

\section{Lifestyle migration, individualization and mobilities}

As has been documented elsewhere (Benson and Osbaldiston, 2014; Benson, 2013b), lifestyle migration has often been adopted as a conceptual framing for research without much thought to the theoretical implications it implies; as a label it is adopted uncritically and rarely problematized by authors. Even among critics (Duncan et al., 2013; McIntyre, 2013), the particular focus on the problematization of migration - and its replacement with mobilities - means that there is a dearth of attention to the intentions behind the use of lifestyle (see also Benson, 2015b). Most of the research conducted in the field tends to use O'Reilly and Benson's (2009:2) ambiguous definition of lifestyle migration as the 'spatial mobility of relatively affluent individuals of all ages, moving either part-time or full-time to places that are meaningful' and which offer 'a better quality of life'. Arguably, the decision to leave this definition loose provides researchers with opportunity to open up and explore the concept of lifestyle further, both theoretically and empirically. Indeed, this disaggregation allows a contemplation of the role of lifestyle within migration, how this makes the migration meaningful for these relatively affluent migrants, but also how lifestyle migration as a social phenomenon is a part of the wider landscape of contemporary migrations (cf. Khoo et al., 2011).

For the most part though, theorizing on lifestyle migration commonly tends to begin with the ideal of 'the better way of life' that participants seek, leading to rather loose descriptions about motivations, imaginings and how people experience their new lives (Benson and Osbaldiston, 2014). Key terms, such as happiness in particular, appear as key social goods that reflexive subjects scurry around trying to secure using all available technical and expert knowledge (Korpela, 2014). The term 'lifestyle' within this revolves around that question of literally 'finding a better way of life' (O'Reilly and Benson, 2009: 3-5).

These discussions therefore engage with limited scope questions that are fundamental to post- or late modern social theory, including consumption and identity, social and economic tensions within the movement, attachment to the immaterial or non-human aspects of place, and questions of otherness within community (Benson, 2011a; Oliver and O'Reilly, 2010; O'Reilly, 2012). In consequence, theorizing about lifestyle migration has tended to use 'safe concepts that come ready-made and can easily be applied to any empirical problem, themes that can easily be fetishized where they are used 'ad nauseum to every 
aspect of social and cultural life' (Gane, 2012: 28). We argue in particular that concepts such as individualization and reflexivity, used repeatedly as foundations for understanding lifestyle migration, are examples of this dilemma (cf. Inglis, 2014).

Theories such as individualization, which privilege agency (at times at a cost), have frequently been the pen which connects the dots of lifestyle migration scholarship (eg D'Andrea, 2007; Korpela, 2009). One of the first attempts to theoretically explore lifestyle migration demonstrates this quite well and is worth citing at length here:

\begin{abstract}
With this in mind, we consider the insights offered by sociological theorists who make explicit the link between consumption and lifestyle (eg Beck, 1992; Bauman, 2000; Giddens, 1991). Common to these accounts is the notion that society has now entered post, late, second, or liquid modernity (depending on the author), characterized by the demise of traditional social structures and divisions of labour, and a greater degree of consumer choice. Lifestyle, within this contemporary consumer society, is a life project for the individual, part of the reflexive project of the self (Giddens, 1991), in which we unremittingly, but never routinely, engage, in order to make sense of who we are and our place in the world. (Benson and O'Reilly, 2009: 616; italics added)
\end{abstract}

The foundation for these particular 'styles' of theoretical thought are that the agency of individuals has dramatically increased leaving the individual freer to choose their actions but also burdened with individual responsibility as the welfare state breaks apart. Lifestyle migration thus becomes symptomatic of reflexive lifestyle choices; intrinsic to this is the suggestion that people reflect on alternative modes of living, rejecting some over others. The use and reuse of these sorts of epoch founding concepts in lifestyle migration research has worked against the idea that we can with patience, reinsert classical and modern theoretical approaches to migration studies to understand this relatively new practice (Favell, 2001).

The mobilities paradigm - characterized by its opposition to the traditional approaches to social science as sedentary, failing to keep up with a world that is forever moving and never fixed (Urry, 2007) - has also been used to problematize lifestyle migration on the grounds, among others, that it overlooks a host of different movements of people, things, images, objects, ideas and capital (Cohen et al., 2013; McIntyre, 2013; Glick Schiller and Salazar, 2013; Salazar, 2011; Vannini and Taggart, 2014). This critique has produced new conceptualizations for understanding the relationship between lifestyle and migration, but these conceptualizations appear to be less driven by empirical data than their precursors.

In what follows, we seek to unpack further how these concepts are used to make sense of lifestyle migration and illustrate how this is demonstrable of a broader problem in sociology. 


\section{Problematizing individualization}

One of the broad assertions social theory has made in recent years has been the ubiquitous claim to the 'freedom' of individuals and their ability to make choices without the shackles of traditional structure through theories such as individualization, liquid modernity and the 'new' individualism (Bauman, 2001; Beck, 1992; Elliot and Lemert, 2009). These approaches rely broadly on the argument that social life is saturated by choice and that individualism is rampant to the point that 'the culture of individualism' not only represents individual choice but also shapes the 'social fabric itself' (Elliot and Lemert, 2009: 3). The life-project is now defined by the ideals of individualism wherein the person is set free to explore identity, choose paths to follow in self-development and acquire new experiences along the way. While the burden of responsibility now lies on the individual's shoulders, the argument for a new epoch of individualism rests on a proliferation of choices and a subject that oscillates between them. The implied sentiment is that these choices are free of the usual structures so central to the oeuvre of classical theory. The use of this style of thought is highly evident in lifestyle migration. For instance, D'Andrea (2007: 9) suggests that subjects in his study into migration were able to 'inhabit a nebula of fluidic and blurred sub-styles' that enables them to 'evade conventional codes defined by modern regimes of the nation-state'; borders are subverted and boundaries traversed.

However, this is empirically problematic. Only a select few of the population will ever have the 'option' of packing up their lives and shifting transnationally for the purposes of pursuing 'the good life', let alone overcoming strong national border issues (Castles and Miller, 2003). Furthermore, the question of whether these choices come freed from structure in the first place is debatable (O'Reilly, 2014). Indeed, the reaction to individualization theses such as those proposed by Beck and Bauman, have met with fierce critique, not least from scholars of class who reassert that class remains a significant structuring force in society (Atkinson, 2007, 2008) and that the ability to choose is a fundamental characteristic of the middle classes, namely, those relatively privileged in the class structure (Savage, 2000; Skeggs, 2004).

The temptation to use theories that privilege individual choice in lifestyle migration stories is understandable; frequently, participants in studies will comment on their new found freedom and control some aspect of their life that provides comfort and something solid (Korpela, 2009; D'Andrea, 2007; Hoey, 2014). In a world that is supposedly becoming more risky, fragmented and fluid, the ability to find something concrete to hold on to is a new cultural desire according to Bauman (2001) and provides explanatory power to a quest for a better life. Yet, as O'Reilly demonstrates, 'the continuing salience of former categories and the reproduction of certain stratifying features of social life' (2009: 117) mean that theories of individualism neglect important aspects of lifestyle migration. It is against this background that we argue against the privileging of individualism in this field. 


\section{Introducing the individualized lifestyle migrant}

The use and reuse of theories of individualism in lifestyle migration is perhaps unsurprising. That the movement is endemic of a late or postmodern world appeared early on to capture a reason why people were seeking a 'better way of life';

[T] hese personalised stories of what appears to be a typical Baumanesque pursuit of the individual good life (Bauman, 2008) must also be understood within their wider sociological, historical and material contexts. The search for a better way of life, which on the surface appears no different to that held by all migrants, is distinctive, reflecting the wider lifestyle choices that individuals in the late, liquid or post-modern world would make on a daily basis. (O'Reilly and Benson, 2009: 3; italics added for emphasis)

There have been limited attempts since this early publication to unpack the broader historically specific traces of lifestyle migration (cf. Hoey, 2006, 2014; O'Reilly, 2000, 2012). As noted above, the underpinning thought that this is a new manifestation of seeking a 'better way of life' has caused several to seek out answers, such as Bauman, Beck and Giddens amongst others. There is, however, a limited understanding of where this idea comes 'from and how' it shapes 'actions and imaginations' (O'Reilly, 2014: 221; cf. Benson, 2012). This traces deeper than social imaginaries into the quest for an authentic life more generally, as made apparent in Benson (2011a, 2013a) and Osbaldiston's (2012) works. Indeed, following Inglis (2014), we could argue that this is evidence of allowing others to do the thinking for us. The use of concepts that are 'periodizing' (such as individualism) tends to 'compel and legitimate disengagement with the serious study of historical processes' (Inglis, 2014: 100-101). In short, they present the contemporary age as completely unique and provide no impetus for comparative analysis of the present with the past. So far in lifestyle migration scholarship, we have done little to connect with not just historical examples (cf. O'Reilly, 2000) but also with other migrations.

\section{Choice within constraint}

It is undoubtedly the case that lifestyle migrants figure as privileged, and yet privilege is produced by structures. Our second point relates to the tendency to begin research into something like lifestyle migration from the standpoint of agency, overlooking the extent to which structural conditions maintain some control over what individuals can do. Despite admitting that lifestyle migrants are 'ideal individualised subjects', Korpela (2014: 41-42) has recently re-evaluated the discourse of choice within lifestyle migration:

... reflections on individuality can easily make it sound as if individuals were independent actors pursuing the good in life as best they can. One must not, however, forget that individuals act within existing structures. They are not free-floating agents ... although lifestyle migrants emphasise their individual agency, their actions are greatly influenced by external factors and structural conditions. (Korpela, 2014: 42) 
Structure thus plays a role in determining not only the ability to migrate but also migrant lives. This argument is well embedded into lifestyle migration literature especially in the work of O'Reilly (2014: 222) who demonstrates the manner in which the social imaginary can be ascribed to a particular 'habitus' within certain classes (see also Benson, 2011a, 2012).

Korpela (2014) is right to assume that there are a number of structural conditions which determine our choices for us, something amenity migration literature also recognizes (see Gosnell and Abrams, 2009). However, a significant consequence of the turn towards understanding social and cultural phenomena through the lens of theories promoting individualism is that the host of structures that continue to dictate choice to individuals (and which frame migrant lives) are not given as much attention as they deserve. Wider structural and material conditions, including socio-economic characteristics such as gender, 'race', ethnicity and class which potentially facilitate, limit and shape action on the basis of choice, are not fully recognized (O'Reilly, 2012). Repositioning individual choices and experiences within these wider conditions undoubtedly provides a more nuanced understanding of migrant lives in lifestyle migration, but also serves to displace the prevailing tendency to perceive this as evidence of individualization. Simply put, recognizing the contexts and conditions within which individual action and experience takes place provides us with insights that contradict this presentation of lifestyle migrants as ideal, individualized subjects.

The value of this can be seen in a number of examples that have recognized how structural and material conditions shape lifestyle migrant lives. Concerns over social class - understood in particularly Bourdieusian terms that incorporate recognition of the role of capitals, assets and resources - underpin the work of Benson on the British in rural France (2011a, 2013a, 2014) and Oliver and O'Reilly's (2010) reconsideration of the British in Spain (cf. O'Reilly, 2009). Class is not only presented as a structure that makes migration possible, but one that is reproduced and reformulated within migrant lives; 'class is a material reality which structures the extent to which people can live in Spain, the manner in which they live and whether they can stay there' (Oliver and O'Reilly, 2010: 63).

In addition to this, Croucher recently advocates the gendering of lifestyle migration research, stressing that ' $\ldots$ gender is implicated in the migration decisions and settlement experiences of relatively affluent border crossers' (2014: 15). One example of this is Lundström's (2014) exemplary account of how whiteness, gender and privilege intersect in the migration of Swedish women to Spain - designated by her as a form of lifestyle migration - and the United States and Singapore. Through this comparison, she identifies the complex ways in which class and racial privilege intersect with gendered vulnerabilities.

Thirdly, despite a tendency toward methodological nationalism within lifestyle migration research, there has been surprising little focus on ethnicidentity/community-making since O'Reilly's (2000) seminal work on the British 
on the Costa del Sol. However, recent research on Latin America has turned towards the critical examination of the racialization of these (often) white migrant populations (Hayes, 2014a). In particular, these works focus on the enhanced visibility of these lifestyle migrants within their new social environments, resulting from the privilege of whiteness within historically racialized social hierarchies. This inclusion of discussions of 'race' and ethnicity within the migrant experience treads familiar territory for migration researchers, but turns the questions asked on their head; rather than questions which focus on how the ethnicization and racialization of migrant populations result in disadvantage, these studies of lifestyle migrants demonstrate how ethnicization and racialization denote privilege.

Such discussions of how structures influence decisions to migrate, the act itself and how they are reproduced through the actions, practices and lived experiences of migrants, are important in making sense of how lifestyle migration relates to wider landscapes of migration theory where structural and material conditions have been central in understanding migration and migrant lives. Recognizing how these operate within the lives of these relatively affluent migrants thus serves a dual purpose, both demonstrating that understanding this social phenomenon as a form of migration is a deliberate and political point while also recognizing that the relative class and racial privilege of these migrants is telling of the power asymmetries at work within global migration flows (Benson, 2013b, 2015a; see also Amit, 2007).

Lastly, while it is clear that there have been significant shifts in our social and institutional worlds through globalization, there are serious questions about whether lifestyle migration research has acknowledged the major structural barriers that limit agency. The significant work in the areas of 'borders', 'immobilities' and other forms of stagnation and stasis in movement warrant some consideration here (Castles, 2013; O'Dowd, 2010; O'Reilly, 2012; Salazar and Smart, 2011). Present literature that continues to lean on the individualism route attracts a major critique in that a significant portion has emerged in the context of a far freer European Union. It is clear that this sort of 'ideal type' of migration does not necessarily compare with the ability for people elsewhere to cross borders. Policies in Asia, North and South America, Oceania and Africa undoubtedly provide restrictions to choices that potential lifestyle migrants seek to make and throw up other structural questions such as power, control and class (Benson, 2013b, 2015a; Croucher, 2009; Khoo et al., 2011; Hayes, 2014a, 2014b).

Aside from persistently strong nation-state border controls, there are other internal dynamics that construct barriers and influence post-migration lives (O'Reilly, 2000, 2012). Indeed, scholars have demonstrated how in the case of North American lifestyle migration to Latin America, privilege within the destination is shaped and 'fractured along lines of class, 'race' and ethnicity' (Benson, 2014: 65, 2015a; cf. Hayes, 2014a). Similarly, in Australia and America, counter-urbanization trends can at times construct powerful sub-group contestations over what are 'authentic' and exposes hierarchies of authority 
within locales (Osbaldiston, 2012). These interpersonal, bureaucratic dynamics and questions of internal/external borders remain powerful instruments in shaping behaviour that cannot be forgotten when exploring the motivations behind and choices within lifestyle migration. Nor should they be forgotten in sociology when dealing with new social and cultural phenomena.

\section{Lifestyle migrants on the move}

One of the emerging paradigms, especially in European social science, that have emerged in recent times is that of mobilities. The depth and breadth of this new form of intellectual inquiry is having a growing influence on the way in which we frame and understand phenomena like lifestyle migration (Benson, 2011b; Duncan et al., 2013; O'Reilly, 2012; Salazar, 2011). This is perhaps true, however, of how we frame movement and indeed the 'social' which for Urry (2007: 1) is now 'on the move' more than ever. While some criticize this transition to a social science without boundaries (Favell, 2001; Franquesa, 2011; Osbaldiston, 2014), there has been a noticeable shift towards unpacking or complicating phenomena like lifestyle migration through a mobilities lens (Bissell and Fuller, 2011; Cohen et al., 2013; McIntyre, 2013; Salazar, 2014). Fundamentally, this approach offers an analysis that privileges the 'impermanence' of migrants and the surrounding objects, capital, imagery, networks, flows and spaces that surround them (McIntyre, 2013; Sheller and Urry, 2006; Urry, 2007). Through the lens of mobilities, 'lifestyle migration' is criticized for excluding the analysis of these other facets of modern life.

\section{Mobilities}

The fundamental purpose of the new mobilities paradigm is to retrain sociological analysis away from what Urry (2007: 19) describes as its sedentary base. The crux of Urry's (2007: 17-20) argument is that social science is illequipped to deal with a world that has intensified movement of not just people but also technological, political, monetary, consumptive and other non-human entities (see also Sheller, 2011). While the traditional social science approach is to 'freeze' these processes in time for analytical purposes, the mobilities paradigm seeks to allow for the complexities and 'unintentional causal processes' of social life to come to the fore (Sheller, 2011: 4). Important forms of social interaction and travel that have previously been ignored, including 'holidaymaking, walking, car-driving, phoning, flying', become important areas for investigation in their own right and in connection with other daily activities where we 'move' (Urry, 2007: 19). Life, it seems, is so frantic and chaotic that we at times strive for those moments that stand still (Bissell and Fuller, 2011).

Consequently, the mobilities paradigm brings a new set of ordering knowledge to the table. As Urry argues, this disciplinary technique requires the development of 'a sociology that focuses upon movement, mobility and contingent ordering, rather than upon stasis, structuring and social order' (2007: 18); using Simmel, he seeks a sociology that provides metaphoric reflection rather 
than freezing in time fragments of modernity. Building on this, Sheller argues further that 'mobilities research .... concerns not only physical movement, but also potential movement, blocked movement, immobilization and forms of dwelling and place-making' (2011: 6; see Salazar and Rivoal, 2013; Salazar and Smart, 2011).

That mobilities can rewrite the sociology of migration has found, perhaps unsurprisingly, strong opposition. Favell offers a significant criticism of the new paradigm, for instance in the following:

As any migration scholar knows, to assess really the extent or nature of the movement, or indeed even see it sometimes, you have in fact to spend a lot of time studying the things that stand still: the borders, institutions and territories of nation-states; the sedimented 'home' cultures of people that do not move. (2001: 391-392; italics added)

The real future, Favell continues, for the development of a sociology of migration is the continuation of 'systematic construction of mid-range empirical theories' and a 'patient reassertion of the insights and methods of past classics' (2001: 393). Further to this, the ability for theoretical assertions bound in metaphors to unpack and make sense of complex structural processes found in border issues (such as visas and immigration policies) is for some problematic (O'Dowd, 2010). In particular, they tend to ignore historical formations of these boundaries and their continued salience in determining trends in migration.

\section{Conceptualizing and evaluating lifestyle mobilities}

As noted above, despite these criticisms, there has been a significant investment and interest in adopting the mobilities paradigm as a frame for understanding lifestyle migration. A good example of this can be found in Duncan et al.'s (2013) edited collection entitled Lifestyle Mobilities. Here, lifestyle migration is critiqued in a few ways. Firstly, the definition of the term as a quest for a 'better way of life' - as characterized by Benson and O'Reilly (2009) - is questioned by Cohen et al. (2013: 5; italics added) as follows:

[W] maintain that to privilege any chosen way of life as 'better' is to potentially offer a romantic reading of it, and that links between romanticism and mobility have a long and critiqued history in nomadology (Cresswell, 2006; Hannam, 2009), embodied in the subject position of the nomad or 'neo-nomad' (for example D'Andrea, 2006).

Rendering Benson and O'Reilly's (2009) position in this manner is problematic in some respects because it fails to acknowledge that this characterization derives from ethnographic work where individuals report their motivation in this way. Furthermore, the intention behind the study of lifestyle migration has been to use these motivations as a way into understanding the practices - including the act of migration and the more mundane, everyday actions through which these migrants make their lives meaningful in these terms (eg Korpela, 2010; Benson, 2011a). Beyond this, however, the characterization of the relationship between romanticism and movement as discussed by Cohen et al. (2013) is not distinct to nomadology, but is long-standing within cultural analysis (finding authenticity); indeed, the acknowledgement of this as a 
social construction informs some research into lifestyle migration (and amenity migration) (see Benson, 2011a, 2013a; Osbaldiston,2011, 2012).

Nevertheless, approaching the movement of people in this way enables, for Cohen et al. (2013:4) a way of recognizing and making sense of the intersections of travel, leisure and migration, an intermediate position between 'temporary mobility' and 'lifestyle migration'. Within this, they present lifestyle migration as a straw man (with the misrepresentation that this permits); for them, lifestyle migration implies permanence, as a one-off act of border-crossing. In this, they overlook the presentation of lifestyle migration as an ongoing quest for a better way of life, 'migration as one lifestyle choice within a wider lifestyle trajectory' (O'Reilly and Benson, 2009: 11; Benson, 2011a) that has been central to conceptualizations of this social phenomenon from the outset.

Lifestyle mobilities allows for the, '[O]ngoing semi-permanent movement of varying durations', 'multiple moorings', 'may involve return to home[s]', 'not fixed', 'varying durations of stay', 'multi-transitional', 'some seasonal variation' and 'ongoing throughout the life-course' (Cohen et al., 2013: 4). They write further,

Unlike permanent migration, lifestyle mobility does not pre-suppose that there is no intention to return. A return to point of origin, or to any other point in the on-going movement process, may be part of lifestyle mobility and so we contend that a return to any identified 'origin' cannot be presumed. (Cohen et al., 2013: 4)

In this way, multiple moorings become the important site for the development of subjectivities, with meaning made through movement. In short, the lifestyle mobile persona is neither permanent nor temporary but occupies a space where the two poles are antagonized and play out in choice. The difficulty for us in such a conceptualization lies in two further directions that we discuss in detail below: (1) the perceived need for a new conceptualization that deals with the welltrodden relationship between migration and tourism; and (2) the lack of clarity about who the phenomenon of lifestyle mobilities might be representative of.

Firstly, we question the need to focus on a typology that sits uncomfortably between tourism and migration when this area has been well considered in both second-home, tourism and even lifestyle migration literature (Benson, 2011a; O'Reilly 2000, 2012; Williams and Hall, 2000). While typologies often do not reflect the messiness of social reality, we remain unconvinced of the need to carve out a new space to discuss those in-between tourism and migration as two established - and in Cohen et al.'s (2013) rendering, essentialized-tropes within sociological thought. Part of this lies in our uncertainty about whether this new conceptualization is emblematic of lifestyle migrant and tourist attitudes. For instance, as we stressed above, the lifestyle migration literature makes clear that these migrants do not necessarily see their move as a single 'one-off event' in the life course, but that it is rather viewed as '.. a relative and ongoing endeavor ... Correspondingly, the act of migration emerges as just one action among many that my respondents undertake before and after migration in their efforts to get to a better way of life' (Benson, 2011a: 155). 
This leads to our second concern, that it is not entirely clear for whom this concept is representative. While lifestyle migration and second-home ownership apply to those who are relatively affluent (Benson and O'Reilly, 2009; Benson, 2013b, 2014; Hall and Müller, 2004; Paris, 2011; cf. Oliver and O'Reilly, 2010) able to trade on the capitals and assets accrued in one location to facilitate a life in another (Hayes, 2014b), the conceptualization of lifestyle mobilities does not make clear to whom it refers. Even the examination of the different chapters included in the edited volume Lifestyle Mobilities (Duncan et al., 2013) does not really help to clarify this; it includes works on how identities are made through travel and movement, a theme notably well-considered in earlier work on migration (see, for example, Rapport and Dawson, 1998), as well as how movement and travel might entail lifestyle. Looking across the chapters, it remains unclear as to the value of lifestyle mobilities as a concept in explaining what are diverse movements (including peripatetic artists, storm-watching and bluewater sailors); why is this not just mobilities?

This is perhaps the result of taking a top-down approach to the development of a concept, but also a focus on process, rather than a people. To our reading, the lifestyle mobile at best can only be representative of a very small segment of society, and begs the question as to the value, politics and ethics of distinguishing the movement practices of these individuals from other 'movements'. It assumes that meaning-making lies in their mobile practices (which may or may not be the case). However, to our minds, the biggest question when approaching this is how this relates to Urry's (2007) agenda in producing a new sociological landscape that seeks to reinvent traditional methods through sociological reasoning.

The answer to this lies perhaps in a chapter from McIntyre who, arguing against migration and counterurbanization, proposes the following:

The emphasis on migration and counterurbanization creates two problems for conceptual clarity. The first is the term migration focuses debate on the mobility of people, which neglects the broad array of other mobilities (Urry, 2000, Sheller and Urry, 2006) or flows (Castell 2000, Appadurai, 1996) that are associated with this voluntary relocation including the movements of capital, information, knowledge and skills. Secondly, the emphasis on rediscovery and flow to large urban areas of professional and managerial elites attracted as much by lifestyle considerations as by employment opportunities (Castells, 2000; Perlik and Messerli, 2004). I argue that this neglect has limited a theoretically integrated analysis of this phenomenon and its wider implications. (2013: 194; italics added)

In short, McIntyre's (2013) argument is based on a critique of lifestyle migration that sees it as fundamentally driven only to understand human motivations - in other words the people involved and their motivations and experiences and a predominant focus within this literature on rural and coastal locations (Benson, 2011a; Osbaldiston, 2012; cf. Griffiths and Maile, 2014). Rather than focus on these, McIntyre (2013) proposes, fundamentally, that mobilities does what migration cannot; he argues that mobilities can open up questions of, 
'how different kinds of lifestyle migrants manage movement, harness technology, and develop social networks to realize their desired projects and plans (for example keeping in contact with friends and relatives, developing a business) while being "on the move"' (McIntyre, 2013: 196). Later he presents an argument that there is a need for a more nuanced view away from the question of conflict between 'in-migrants and locals' (McIntyre, 2013: 200). Specifically, McIntyre's proposal is that the 'imagined worlds of mobile newcomers and those of the emplaced traditional inhabitants, can variously conflict and align as controversial situations develop' (2013: 200).

This seems a re-envisioning of what is essentially a well-trodden theme in sociology - and therefore not distinct to mobilities - developing out of the work of Ray Pahl (1965) - but also one that is at the core of the lifestyle migration literature (eg Waldren, 1996; Benson, 2011; Osbaldiston, 2012; O'Reilly, 2000). Interestingly, the other concern about the spatial dimensions of the phenomenon is not further developed. While we can agree that better understandings of lifestyle migration might be made possible by locating it within the literature on residential practices - particularly considering that ' $[\mathrm{O}] \mathrm{ne}$ 's residence is a crucial, perhaps the crucial, identifier of who you are' (Savage et al., 2005: 207; original italics) - it is unclear why mobilities would provide this stopgap.

In sum, we remain unsure as to what mobilities as a lens might uniquely add to understandings of lifestyle migration. There is perhaps a need to step back both as scholars of lifestyle migration and of mobilities - and question what the social theory that we are using is doing for us and to our concepts. In particular, with an eye towards the structural and historical, we argue that mobilities has caused us to forget our disciplinary roots and overlook some rather substantial recurring features of migration and cultural phenomena in general.

\section{Conclusion: towards a critical sociology of lifestyle migration}

Through its focus on lifestyle migration research, this paper has laid bare a recurring problem in sociology: the retreat to 'ready-made' concepts that, as Inglis (2014:114) argues, promote a paradigm that temporally locates us in historically unprecedented times. The consequence of this is the disengagement of researchers from approaching social and cultural phenomena with more nuanced and perhaps humble theoretical logics. We have argued above that in lifestyle migration scholarship, this is a particular problem. The turn towards the new theories of individualism and mobilities has made sense of data gathered in a particularly simplistic way, dismissing powerful constructs such as status, class and other structural components. Furthermore, these paradigms tend to focus our theorizing on lifestyle migration towards the present, ignoring connections to the past and other 'migrations'.

With this in mind, we conclude with what we believe are steps towards a 'critical sociology of lifestyle migration'. We argue that lifestyle migration may well be best considered as what Weber (2012 [1904]) once described as an 
'ideal type', 'simply building blocks for clarifying our thinking' (Scaff, 2014: 46). From this perspective, the important concept to lay hold of here is 'lifestyle'. For O'Reilly (2014), this means interrogating issues such as the individual and cultural imagining that underpins the motivation to 'lifestyle migrate' and which subsequently structures migrant lives (see also Benson, 2015b). While imagination here can be attributed to the habitus and class/status position of the individual, there are others who turn to broader national or collective narratives that guide a type of collective nostalgia and valuation towards certain places (Osbaldiston, 2012). Seen through this lens, 'lifestyle' is context specific, fractured across social groups and nationalities that may well have different conceptions of the 'lifestyle' that feed into a desire to migrate; in other words, while lifestyle migration remains an important way of framing the movement of people seeking a 'better way of life', the specifics of lifestyle can be quite different.

With this in mind, we argue that the concept of lifestyle migration has been used rather uncritically to explain various migration flows, with little account for the cultural differences that may frame imaginings of lifestyle. Turning a critical lens onto this literature demonstrates the impact of eurocentrism captured particularly in equating individualism with freedom of movement, in a context where the ability to migrate between European nations is relatively easy. One consequence of this has been that questions of ethnic relations, power and contestation, boundaries and potential economic disparities between migrants and host community members have been rather underexplored (cf. Benson, 2013b, 2015a; Croucher, 2009; Hayes, 2014b). Using assumptions such as those buried within individualization theses tends to overlook or attune the theoretical eye away from issues of political and economic power. What is yet to be made clear, in a sense, is the continuing impact and organization of lifestyle migration as a concept amongst other migratory issues (Castles and Miller, 2003). In particular, as we shift further into the post-global financial crisis phase of global economics and a deepening of inequality between the supposed North and South countries, lifestyle migration and its twin, labour migration, need to be considered in more detail together.

At a broader level, lifestyle migration also appears as one of those important artefacts of contemporary modernity to which sociology can turn to reconsider concepts, organize thoughts on structure, and test the assumptions built into social theory. As a movement that is both inherently global and local, the importance of sociology to interrogate this as an important site for understanding the 'social' is clear. As we have illustrated here, the relationship between structure and freedom is writ large in lifestyle migration; the sites of research, and indeed the peoples studied, may also cause us to question the value of adopting European social theory to explore global contexts. But it is also clear that lifestyle migration speaks to broader macroeconomic and geopolitical issues which transcend nation-state boundaries and provide important case studies into the globalization of culture. As O'Reilly reminds us, even if the migrant is motivated by a social imaginary that is developed while in their home country, 
these imaginations are hence 'enacted and shaped by other actors than just migrants' (2014: 231). It is these different narratives that we argue need sociological reasoning and include a wide toolkit of concepts from power to agency, class to status and freedom to consequence.

Goldsmiths, University of London

Received 14 November 2014

James Cook University

Finally accepted 13 July 2015

\section{References}

Amit, V., (2007), 'Structures and dispositions of travel and movement', in V. Amit (ed.), Going First Class? New Approaches to Privileged Travel and Movement, 1-14, Oxford: Berghahn.

Atkinson, W., (2007), 'Beck, individualization and the death of class: a critique', The British Journal of Sociology, 58: 349-366.

Atkinson, W., (2008), 'Not all that was solid has melted into air (or liquid): a critique of Bauman', The Sociological Review, 56 (1): 1-17.

Bauman, Z., (2001), The Individualized Society, Cambridge: Polity Press.

Beck, U., (1992), Risk Society: Towards a New Modernity, M. Ritter (trans.), London: Sage.

Benson, M., (2011a), The British in Rural France: Lifestyle Migration and the Ongoing Quest for a Better Way of Life, Manchester: Manchester University Press.

Benson, M., (2011b), 'The movement beyond (lifestyle) migration: mobile practices and the constitution of a better way of life', Mobilities, 6 (2): 221-235.

Benson, M., (2012), 'How culturally significant imaginings are translated into lifestyle migration', Journal of Ethnic and Migration Studies, 38 (10): 1681-1696.

Benson, M., (2013a), 'Living the "real" dream in la France Profonde? Lifestyle migration, social distinction and the authenticities of everyday life', Anthropological Quarterly, 86 (2): 501-526.

Benson, M., (2013b), 'Postcoloniality and privilege in new lifestyle flows: the case of North Americans in Panama', Mobilities, 8 (3): 313-330.

Benson, M., (2014), 'Negotiating privilege in and through lifestyle migration', in M. Benson and N. Osbaldiston (eds), Understanding Lifestyle Migration: Theoretical Approaches to Migration and the Quest for a Better Way of Life, 47-70, Basingstoke: Palgrave Macmillan.

Benson, M., (2015a), 'Class, race, privilege: structuring the lifestyle migrant experience in Boquete, Panama', Journal of Latin American Geography, 14 (1): 19-37.

Benson, M., (2015b), 'Lifestyle migration: from the state of the art to the future of the field', Two Homelands, 42: 9-23.

Benson, M. and O'Reilly, K., (2009), 'Migration and the search for a better way of life: a critical exploration of lifestyle migration', The Sociological Review, 57 (4): 608-625.

Benson, M. and Osbaldiston, N. (eds), (2014), Understanding Lifestyle Migration: Theoretical Approaches to Migration and the Quest for a Better Way of Life, Basingstoke: Palgrave Macmillan.

Bissell, D. and Fuller, G. (eds), (2011), Stillness in a Mobile World, London: Routledge.

Castles, S., (2013), 'The forces driving global migration', Journal of Intercultural Studies, 34 (2): 122-140.

Castles, S. and Miller, M., (2003), The Age of Migration, New York: Guilford Press.

Cohen, S., Duncan, T. and Thulemark, M., (2013), 'Introducing lifestyle mobilities', in T. Duncan, S. Cohen and M. Thulemark (eds), Lifestyle Mobilities: Intersections of Travel, Leisure and Migration, 1-18, London: Ashgate.

Croucher, S., (2009), The Other Side of the Fence: American Migrants in Mexico, Austin: University of Texas Press.

Croucher, S., (2014), 'Gendered spatialities of lifestyle migration', in M. Janoschka and H. Haas (eds), Contested Spatialities, Lifestyle Migration and Residential Tourism, 15-28, London: Routledge. 
D'Andrea, A., (2007), Global Nomads: Techno and New Age as Transnational Countercultures, London: Routledge.

Duncan, T., Cohen, S. and Thulemark, M. (eds), (2013), Lifestyle Mobilities: Intersections of Travel, Leisure and Migration, Farnham: Ashgate.

Elliot, A. and Lemert, C., (2009), The New Individualism: The Emotional Costs of Globalisation, London: Routledge.

Favell, A., (2001), 'Migration, mobility and globaloney: metaphors and rhetoric in the sociology of globalization', Global Networks, 1 (4): 389-398.

Franquesa, J., (2011), 'We've lost our bearings: place, tourism, and the limits of the mobility turn', Antipode, 43 (4): 1012-1033.

Gane, N., (2012), Max Weber and Contemporary Capitalism, Basingstoke: Palgrave Macmillan.

Glick Schiller, N. and Salazar, N., (2013), 'Regimes of mobility across the globe', Journal of Ethnic and Migration Studies, 39 (2): 183-200.

Gosnell, H. and Abrams, J., (2009), 'Amenity migration: diverse conceptualizations of drivers, socioeconomic dimensions and emerging challenges', Geojournal, 76: 303-322.

Griffiths, D. and Maile, S., (2014), 'Britons in Berlin: imagined cityscapes, affective encounters and the cultivation of the self', in M. Benson and N. Osbaldiston (eds), Understanding Lifestyle Migration: Theoretical Approaches to Migration and the Quest for a Better Way of Life, 139-162, Basingstoke: Palgrave Macmillan.

Hall, C. M. and Müller, D. K. (eds), (2004), Tourism, Mobility and Second-homes: Between Elite Landscape and Common Ground, Clevedon: Channel View Publications.

Hayes, M., (2014a), " "It is hard being the different one all the time": gringos and racialized identity in lifestyle migration Ecuador', Ethnic and Racial Studies (Online First).

Hayes, M., (2014b), " "We gained a lot over what we would have had": the geographic arbitrage of North American lifestyle migrants to Cuenca, Ecuador', Journal of Ethnic and Migration Studies, 40 (12): 1953-1971.

Hoey, B., (2006), 'Grey suit or brown carhartt: narrative transition, relocation and reorientation in the lives of corporate refugees', Journal of Anthropological Research, 62 (3): 347-371.

Hoey, B., (2014), Opting for Elsewhere: Lifestyle Migration in the American Middle Class, Nashville: Vanderbilt University Press.

Inglis, D., (2014), 'What is worth defending in sociology today? Presentism, historical vision and the uses of sociology', Cultural Sociology, 8 (1): 99-118.

Khoo, S., Hugo, G. and McDonald, P., (2011), 'Skilled migration from Europe to Australia', Population, Space and Place, 17: 550-566.

Korpela, M., (2009), 'When a trip to adulthood becomes a lifestyle: the community of Westerners in Varanasi, India', in M. Benson and K. O'Reilly (eds), Lifestyle Migration: Expectations, Aspirations and Experience, 15-30, Aldershot: Ashgate.

Korpela, M., (2010), 'A postcolonial imagination? Westerners searching for authenticity in India', Journal of Ethnic and Migration Studies, 36 (8): 1299-1315.

Korpela, M., (2014), 'Lifestyle of freedom? Individualism and lifestyle migration', in M. Benson and N. Osbaldiston (eds), Understanding Lifestyle Migration: Theoretical Approaches to Migration and the Quest for a Better Way of Life, 27-46, Basingstoke: Palgrave Macmillan.

Lundström, C., (2014), White Migrations. London: Palgrave Macmillan.

McIntyre, K., (2013), 'Mobilities, lifestyles and imagined worlds: exploring the terrain of lifestyle migration', in T. Duncan, S. Cohen and M. Thulemark (eds), Lifestyle Mobilities: Intersections of Travel, Leisure and Migration, Farnham: Ashgate.

O'Dowd, L., (2010), 'From a borderless world to a world of borders: bringing history back in', Environment and Planning D, 28: 1031-1050.

Oliver, C. and O'Reilly, K., (2010), 'A Bourdieusian analysis of class and migration habitus and the individualizing process', Sociology, 44 (1): 49-66.

O'Reilly, K., (2000), The British on the Costa del Sol, London: Routledge.

O'Reilly, K., (2009), 'The children of the hunters: self-realisation projects and class reproduction', in M. Benson and K. O'Reilly (eds), Lifestyle Migration: Expectations, Aspirations and Experience, 103-20, Aldershot: Ashgate. 
O'Reilly, K., (2012), International Migration and Social Theory, Basingstoke: Palgrave Macmillan. O'Reilly, K., (2014), 'The role of the social imaginary in lifestyle migration: employing the ontology of practice theory', in M. Benson and N. Osbaldiston (eds), Understanding Lifestyle Migration: Theoretical Approaches to Migration and the Quest for a Better Way of Life, 211-234, Basingstoke: Palgrave Macmillan.

O'Reilly, K. and Benson, M., (2009), 'Lifestyle migration: escaping to the good life?' in M. Benson and K. O'Reilly (eds) Lifestyle Migration: Expectations, Aspirations and Experiences, 1-13, Aldershot: Ashgate.

Osbaldiston, N., (2011), 'The authentic place in amenity migration discourse', Space and Culture, 14 (2): 214-226.

Osbaldiston, N., (2012), Seeking Authenticity in Place, Culture and Self, New York: Palgrave Macmillan.

Osbaldiston, N., (2014), 'Beyond ahistoricity and mobilities in lifestyle migration research', in M. Benson and N. Osbaldiston (eds), Understanding Lifestyle Migration: Theoretical Approaches to Migration and the Quest for a Better Way of Life, 163-187, Basingstoke: Palgrave Macmillan.

Pahl, R., (1965), Urbs in Rure: Metropolitan Fringe in Hertfordshire, London: LSE.

Paris, C., (2011), Affluence, Mobility and Second Home Ownership, London: Routledge.

Rapport, N. and Dawson, A., (1998), Migrants of Identity: Perceptions of Home in a World of Movement. Oxford: Berg.

Salazar, N., (2011), 'The power of imagination in transnational mobilities', Identities, 18 (6): 576598.

Salazar, N., (2014), 'Migrating imaginaries of a better life ... until paradise finds you', in M. Benson and N. Osbaldiston (eds), Understanding Lifestyle Migration, 119-138, Basingstoke: Palgrave.

Salazar, N. and Rivoal, I., (2013), 'Contemporary ethnographic practice and the value of serendipity', Social Anthropology, 21 (2): 178-185.

Salazar, N. and Smart, A., (2011), 'Anthropology takes on (im) mobility', Identities, 18 (6): 1-9.

Savage, M., (2000), Class Analysis and Social Transformation, London: Open University Press.

Savage, M., Bagnall, G. and Longhurst, B., (2005), Globalisation and Belonging, London: Sage.

Scaff, L., (2014), Max Weber in America. Princeton, NJ: Princeton University Press.

Sheller, M., (2011), 'Mobility', Sociopedia.isa, available at: www.sagepub.net/isa/resources/ pds/mobility.pdf.

Sheller, M. and Urry, J., (2006), 'The new mobilities paradigm', Environment and Planning A, 38 (2): 207-226.

Skeggs, B., (2004), Class, Self, Culture, London: Routledge.

Urry, J., (2007), Mobilities, Cambridge: Polity Press.

Vannini, P. and Taggart, J., (2014), 'No man can be an island: lifestyle migration, stillness and the new quietism', in M. Benson and N. Osbaldiston (eds), Understanding Lifestyle Migration: Theoretical Approaches to Migration and the Quest for a Better Way of Life, 188-210, Basingstoke: Palgrave Macmillan.

Waldren, J., (1996), Insiders and Outsiders: Paradise and Reality in Mallorca, New York: Berghahn Books.

Weber, M., (2012 [1904]), "The "objectivity" of knowledge in social science and social policy", in H. H. Bruun and S. Whimster (eds), Max Weber: Collected Methodological Writings, 100-138, London: Routledge.

Williams, A. M. and Hall, C. M., (2000), 'Tourism and migration: new relationships between production and consumption', Tourism Geographies, 2 (1): 5-27.

Please quote the article DOI when citing SR content, including monographs. Article DOIs and "How to Cite" information can be found alongside the online version of each article within Wiley Online Library. All articles published within the SR (including monograph content) are included within the ISI Journal Citation Reports ${ }^{\circledR}$ Social Science Citation Index. 